\title{
EFEITOS DO SEXO E DO TEMPO DE MATURAÇÃO SOBRE A GUALIDADE DA CARNE OVINA ${ }^{1}$
}

\author{
Lorrance A. G. GONÇALVES ${ }^{2}$, Jorge F.F. ZAPATA ${ }^{2, *}$, Maria do Carmo P. RODRIGUES ${ }^{2}$,
}

\author{
Ângela S. BORGES ${ }^{2}$
}

\section{RESUMO}

Foi realizado um estudo para verificar os efeitos do sexo e do tempo de maturação sobre a qualidade da carne de alguns cortes de ovinos. Foram utilizados os músculos Longissimus dorsi e Semimembranosus de cinco machos inteiros, cinco machos castrados e cinco fêmeas, com peso aproximado de $35 \mathrm{~kg}$. As variáveis $\mathrm{pH}$, índice de fragmentação miofibrilar, perdas na cocção, força de cisalhamento, gordura intramuscular, cor e maciez sensorial foram determinadas após $1,3,7$ e 14 dias de maturação da carne em refrigeração a $2^{\circ} \mathrm{C}$. A carne dos machos castrados e a das fêmeas apresentaram menor força de cisalhamento e maior maciez sensorial do que as de macho inteiro. $\mathrm{Na}$ carne de animais castrados foi observado um maior nível de gordura e menores perdas na cocção que na dos animais inteiros. O tempo de maturação da carne não afetou significativamente $(\mathrm{p}>0,05)$ a força de cisalhamento e maciez sensorial, indicando que a comercialização da carne destes animais, principalmente a dos machos castrados, poderá ser realizada com um dia (24 horas) de acondicionamento sob refrigeração a $2^{\circ} \mathrm{C}$.

Palavras-chave: força de cisalhamento; indice de fragmentação miofibrilar; perdas na cocção; maciez sensorial.

\section{SUMMARY}

THE EFFECTS OF SEX AND AGING ON LAMB MEAT QUALITY. A study to verify the effects of sex and aging time of selected carcass cuts on meat quality was conducted. Longissimus dorsi and Semimembranous muscles from five intact males, five castrated males and five female lambs with average slaughter weight of about 35kg were used. Meat pH, myofibrillar fragmentation index, cooking losses, shear force, intramuscular lipids, color and sensorial tenderness were measured after 1, 3, 7 and 14 days of aging at $2^{\circ} \mathrm{C}$. Meat from castrated males and from female lambs showed lower shear force values than those from intact male lambs. Higher levels of fat and lower cooking losses were observed in meat from castrated animals related to those from intact lambs. Aging time did not significantly (p>0.05) affect shear force or sensory tenderness of meats. This observation suggests that lamb meat, mainly from castrated males, can enter the fresh meat market soon after holding carcasses for 24 hours at $2^{\circ} \mathrm{C}$.

Keywords: shear force; myofibrillar fragmentation index; cooking losses; sensorial tenderness.

\section{1 - INTRODUÇÃO}

Os principais fatores que contribuem para a qualidade da carne são a textura, sabor, cor, aparência e odor. Embora o consumidor avalie apenas os aspectos da qualidade visual da carne crua, como a cor do músculo e da gordura, proporção músculo/gordura, marmorização e firmeza do tecido muscular, a textura também deveria ser determinante na hora da compra [35]. Segundo LAWRIE [27], a textura visível é função do tamanho dos feixes de fibras que é determinado não somente pelo número de fibras, mas também pelo diâmetro destes. $\mathrm{O}$ diâmetro das fibras musculares da carne ovina, menor que o das suína e bovina, tende a aumentar levemente com a idade, dando uma característica de maior firmeza a essa carne [49].

$\mathrm{O}$ amaciamento progressivo da carne durante períodos variáveis de acondicionamento da carcaça ou de cortes comerciais sob refrigeração, chamado de maturação, tem sido extensivamente estudado [20, 21, 27]. Durante este período, as enzimas proteolíticas do músculo, notadamente as calpaínas, enzimas dependentes de

\footnotetext{
1. Recebido para publicação em 08/09/2003. Aceito para publicação em 05/07/2004 (001211).

2. Departamento de Tecnologia de Alimentos, Universidade Federal do Ceará, Caixa Postal 12168, CEP: 60020-181, Fortaleza, CE. E-mail: zapata@ufc.br

* A quem a correspondência deve ser enviada.
}

cálcio, agem produzindo degradação parcial da integridade estrutural do sarcômero [29]. Apesar da possibilidade do processo de maturação estar influenciado por fatores como sexo, alimentação e outros, é comumente reconhecido que o mecanismo de amaciamento da carne é o mesmo em todos os tipos de músculos e espécies de animais produtores de carne [34]. Contudo, para se conseguir um ótimo amaciamento da carne durante o período de maturação, é necessário que os animais apresentem, no momento do abate, níveis adequados de glicogênio muscular que permitam a obtenção de valores de pH final da carne em torno de 5,5 [28].

O estudo da textura da carne pode ser feito mediante medição de parâmetros físicos ou através da avaliação sensorial por provadores treinados e padronizados. O método físico de medir a força de cisalhamento através de uma célula de Warner-Bratzler tem sido bastante utilizado, tendo-se encontrado uma alta correlação deste com a análise sensorial da carne [33]. BOLEMAN et al. [6], de acordo com os resultados encontrados na análise de força de cisalhamento pelo método de WarnerBratzler, classificaram a textura da carne em muito macia $(2,3$ a $3,6 \mathrm{~kg})$, moderadamente macia $(4,1$ a $5,4 \mathrm{~kg})$ e pouco macia (5,9 a 7,2kg). SHACKELFORD et al. [39] sugeriram o valor de $4,6 \mathrm{~kg}$ de força de cisalhamento, pelo método de Warner-Bratzler, como padrões sendo o limite aceitável para a comercialização da carne bovina.

A fragmentação miofibrilar pode ser utilizada para medir a tenderização da carne [10]. Esta é uma medida do comprimento médio das miofibrilas, onde miofibri- 
las mais curtas refletem um maior índice de fragmentação miofibrilar [44].

Recentemente, a determinação do comprimento do sarcômero mediante difração de raios laser, tem sido utilizada como forma de avaliação da integridade das miofibrilas da carne [28].

O presente trabalho teve como objetivo verificar o efeito do sexo do animal e do tempo de maturação de alguns cortes sobre as características físicas e sensoriais da carne ovina.

\section{2 - MATERIAL E MÉTODOS}

\section{1 - Procedência da carne e preparação das amos- tras}

Foram utilizados 15 animais ovinos, sendo 5 machos inteiros, 5 machos castrados e 5 fêmeas, do tipo Sem Raça Definida (SRD), criados em regime semi-intensivo, com idade aproximada de 15 meses, ou 2 dentes permanentes e com peso médio de aproximadamente $35 \mathrm{~kg}$.

As operações de abate foram realizadas de acordo com os métodos recomendados pelo Regulamento de Inspeção Industrial de Produtos de Origem Animal [7] em frigorífico industrial. As carcaças foram acondicionadas em câmara a $2^{\circ} \mathrm{C}$ e resfriadas por 12 horas. Os lombos e as pernas de cada carcaça foram utilizados para se obter os músculos Longissimus dorsi, entre a 7av vértebra torácica e 5 $5^{\text {a }}$ vértebra lombar, e os músculos Semimembranosus, respectivamente.

Os músculos L. dorsi, direito e esquerdo (10 peças por sexo), foram cortados em 12 bifes de $2,5 \mathrm{~cm}$ de espessura. Os oito primeiros bifes de cada músculo (direito e esquerdo), no sentido cranial-caudal, foram destinados à determinação de força de cisalhamento, os dois bifes seguintes de cada lado, para a análise da cor e $\mathrm{pH}$, e os dois últimos bifes de cada lado para a determinação do índice de fragmentação miofibrilar e gordura intramuscular. Todos os bifes foram embalados individualmente a vácuo, em filme flexível de alta barreira ao oxigênio. Os bifes foram agrupados por tipo de determinação e em seguida distribuídos, ao acaso, entre quatro tempos de maturação a $2^{\circ} \mathrm{C}$ de temperatura: 1 , 3, 7 e 14 dias, contados a partir do dia do abate. Após a colheita dos bifes, em cada tempo de maturação, os mesmos foram congelados e mantidos a $-18^{\circ} \mathrm{C}$ até o momento da análise.

Os músculos Semimembranosus de cada perna (10 peças por cada sexo), destinados à análise sensorial de maciez da carne, foram cortados pela metade, no eixo longitudinal das fibras musculares, sendo embalado cada fragmento muscular da mesma forma descrita acima. Os quatro fragmentos musculares da perna de cada animal foram distribuídos, ao acaso, entre cada um dos tempos de maturação a $2^{\circ} \mathrm{C}$ (1, 3, 7 e 14 dias). As amostras colhidas foram congeladas e mantidas a $-18^{\circ} \mathrm{C}$ até o momento da avaliação sensorial.

\section{2 - Análises na carne maturada}

As análises das carnes foram realizadas após um período de 18 horas de descongelamento na embalagem, a $5^{\circ} \mathrm{C}$.

$\mathrm{O}$ pH da carne foi medido segundo o método descrito por BELTRÁN et al. [5]. Aproximadamente $3 g$ da porção muscular do bife foram homogeneizados com $20 \mathrm{~mL}$ de água destilada por 15 segundos. Em seguida, o $\mathrm{pH}$ foi determinado com medidor digital de $\mathrm{pH}$ (Digimed, modelo DMPH-2, São Paulo) provido de eletrodo de vidro (Analyser, modelo 2A09E, São Paulo).

$O$ índice de fragmentação miofibrilar da carne foi determinado de acordo com CULLER et al. [10]. De cada amostra, ainda congelada, foram retirados três cilindros de $1,27 \mathrm{~cm}$ de diâmetro, os quais foram picados com tesoura, retirando-se qualquer tecido conectivo ou gordura aparente. Quatro gramas do músculo picado foram homogeneizados em triturador (Marconi, modelo TE102, Piracicaba, São Paulo) por 30 segundos, com $40 \mathrm{~mL}$ da solução de extração contendo $\mathrm{KCl} 100 \mathrm{mM}$, fosfato de potássio $20 \mathrm{mM}$, EDTA $1 \mathrm{mM}, \mathrm{MgCl}_{2} 1 \mathrm{mM}$ e azida sódica $1 \mathrm{mM}$. Em seguida, a solução homogeneizada foi centrifugada, por 15 minutos, a $1000 \mathrm{xg}$, a $4^{\circ} \mathrm{C}$ (Beckman, modelo J2-21, rotor JA-17). Após descartar o sobrenadante, o precipitado foi disperso com $40 \mathrm{~mL}$ da solução de extração, agitado com um bastão de vidro e centrifugado novamente, por 15 minutos, a $1000 \mathrm{x}$ g, a $4^{\circ} \mathrm{C}$. Após descartar o sobrenadante, ao precipitado foram adicionados $10 \mathrm{~mL}$ da solução de extração e a suspensão obtida foi passada através de peneira de polietileno para remoção do tecido conectivo. Mais $10 \mathrm{~mL}$ da solução de extração foram utilizados para lavar e facilitar a passagem das miofibrilas através da peneira. Na suspensão de miofibrilas foi determinada a concentração de proteína pelo método do biureto, descrito por GORNALL, BARDAWILL \& DAVID [17]. Uma alíquota da suspensão de miofibrilas foi então diluída com a solução de extração até uma concentração protéica de $0,5 \pm 0,05 \mathrm{mg} / \mathrm{mL}$. A suspensão diluída de miofibrilas foi agitada e colocada na cubeta, sendo logo em seguida feita a leitura da densidade ótica a 540nm em espectrofotômero (Ultrospec 1000 Pharmacia Biotech, Cambridge, Inglaterra). Para obtenção do índice de fragmentação miofibrilar, foi multiplicado o valor obtido de densidade ótica a 540nm por 200.

As perdas na cocção da carne foram determinadas de acordo com DUCKETT et al. [12]. Os bifes foram pesados e em seguida cozidos em forno elétrico pré-aquecido a $170^{\circ} \mathrm{C}$, até que a temperatura interna atingisse $71^{\circ} \mathrm{C}$ no centro geométrico. Os bifes foram retirados do forno e pesados novamente. A perda de peso durante a cocção foi expressa como percentual do peso da carne antes da cocção.

A textura foi avaliada através da medida de força de cisalhamento. Após a cocção descrita acima, os bifes foram resfriados a $5^{\circ} \mathrm{C}$ por 24 horas. Posteriormente, de cada bife foram retirados dois cilindros de 1,27 de diâmetro, no sentido das fibras musculares. Os cilin- 
dros foram cortados transversalmente utilizando-se um texturômetro TA.XT2 (Stable Micro System, Surrey, England) equipado com uma lâmina tipo Warner Bratzler, operando a $20 \mathrm{~cm} / \mathrm{min}$, conforme DUCKETT et al. [13]. O pico da força de cisalhamento foi registrado, sendo o resultado expresso em $\mathrm{kg}$.

A determinação de gordura intramuscular foi realizada mediante extração com hexano em equipamento de Soxlhet, de acordo com o procedimento descrito pela AOAC [4]. O peso da gordura extraída foi relacionado, percentualmente, ao peso da carne úmida.

A medida de cor foi feita de acordo com ABULARACH, ROCHA \& FELÍCIO [2]. Utilizou-se o colorímetro Minolta CR300 (Minolta Co., Osaka, Japão), medindo-se as unidades L* (luminosidade), a* (intensidade da cor vermelha) e b* (intensidade da cor amarela) do sistema CIE (Commissiom Internationale de l'Eclairage) [30]. Após o descongelamento, as embalagens das amostras foram abertas e a superfície dos bifes exposta ao ar sob refrigeração a $5^{\circ} \mathrm{C}$ por 30 minutos, para permitir a oxigenação superficial da mioglobina. Foram realizadas três medidas por ponto, em três diferentes pontos do bife, anotando-se os valores médios de $\mathrm{L}^{*}, \mathrm{a}^{*} \mathrm{e} \mathrm{b}^{*}$.

Como a medição instrumental de textura não detectou efeito $(p>0,05)$ do tempo de maturação da carne, a análise da maciez sensorial foi realizada em uma única oportunidade, com 3 dias de armazenamento a $2^{\circ} \mathrm{C}$. Para isso, as amostras dos três tipos de animais (macho inteiro, macho castrado e fêmea) foram cortadas em bifes de $2,5 \mathrm{~cm}$ de espessura. Após a cocção, realizada da mesma forma descrita acima para perdas na cocção, foram retirados cubos de $1 \times 1 \times 2,5 \mathrm{~cm}$ e servidos imediatamente aos provadores, segundo DUCKETT et al. [12].

Foi aplicado o teste de ordenação, seguindo-se o delineamento experimental de blocos completos balanceados, descrito por STONE \& SIDEL [42]. Este teste foi realizado em duas sessões, com 21 provadores em cada uma delas. Antes de testar os provadores receberam instruções básicas sobre o procedimento de avaliação das amostras. Cada provador avaliou as três amostras simultaneamente, em cabines individuais, sob luz vermelha. As amostras foram apresentadas de forma aleatória e em ordem balanceada em relação aos provadores e ordenadas em ordem crescente, com relação ao atributo maciez ( $1=$ amostra menos macia e $3=$ amostra mais macia). Para remover o sabor residual entre as amostras foram servidos biscoitos "creamcracker" e água à temperatura ambiente.

\section{3 - Análise estatística}

Os dados de pH, IFM, perdas na cocção, força de cisalhamento e cor foram submetidos à análise descritiva segundo BUSSAB \& MORETTIN [8]. Para verificar os efeitos do sexo do animal e do tempo de maturação da carne sobre as variáveis, foi aplicada análise de variância, e para comparações entre médias o teste de Tukey ao nível de 5\% de significância [32]. Os cálculos foram efetuados utilizando o procedimento GLM do programa computacional SAS (SAS Institute, Carry, USA).
Os dados da análise sensorial foram analisados através do teste de Friedman [42], utilizando-se a tabela de Newell e MacFarlane [1].

\section{3 - RESULTADOS E DISCUSSÃO}

\section{1 - pH da carne ovina}

Os valores de $\mathrm{pH}$ encontrados neste trabalho variaram entre 5,40 e 5,77 (Figura 1), os quais foram similares aos encontrados por outros autores no músculo ovino Longissimus [36, 37, 38, 47]. Os resultados acima confirmam o fato de que a carne ovina raramente apresenta problemas relacionados com $\mathrm{pH}$, como a ocorrência de carne escura seca e firme ou pálida suave e gotejante. Os animais ovinos parecem dispor de mecanismos de adaptação melhores que os dos bovinos e suínos para condições de estresse que ocorrem no transporte e abate [36]. Valores de pH entre 5,4 e 5,9 são desejáveis também porque carnes ovinas com valores acima de 6,0, apesar de apresentarem maciez satisfatória, são consideradas inadequadas para a embalagem a vácuo, devido a sua vida-de-prateleira ser reduzida [11].

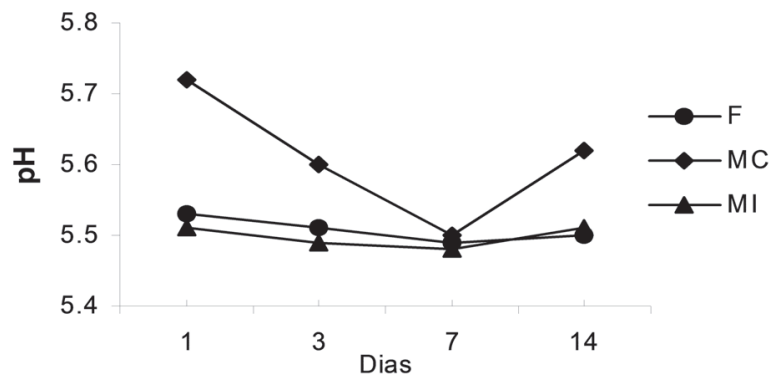

FIGURA 1. Valores de $\mathrm{pH}$ da carne ovina, proveniente de fêmea (F), macho castrado (MC) e macho inteiro (MI), mantida durante 14 dias de maturação a $2^{\circ} \mathrm{C}$.

Quanto ao efeito do sexo, o valor médio de $\mathrm{pH}$ da carne de macho castrado de 5,61 , foi superior $(\mathrm{p}=0,0001)$ ao de fêmea $(5,51)$ e de macho inteiro $(5,5)$, os quais não diferiram entre si. O maior valor de $\mathrm{pH}$ da carne de macho castrado pode ter ocorrido em decorrência da baixa quantidade de glicogênio no músculo destes animais, no abate. SAÑUDO et al. [38], trabalhando com ovinos de clima temperado, também não observaram diferença relevante no $\mathrm{pH}$ entre a carne de macho inteiro e a de fêmea.

Com relação ao efeito do tempo de maturação, foi encontrado efeito significativo $(\mathrm{p}=0,0092)$ no sétimo dia de maturação, quando o pH da carne baixou para 5,49, em relação ao do início da maturação $(5,59)$. Após a morte do animal, um declínio gradual do $\mathrm{pH}$, desde valores próximos a neutralidade, no animal vivo, até 5,4 a 5,7 na carne, é resultado da glicólise e do acúmulo de ácido lático [18].

\section{2 - Índice de fragmentação miofibrilar (IFM)}

Os valores obtidos para o IFM podem ser observados na Figura 2. Foi detectada interação entre o sexo e 
o tempo de maturação. No primeiro dia após a morte do animal, não houve efeito significativo de sexo, sendo o valor médio do IFM de 96,05. No terceiro dia post mortem, o valor médio do IFM $(129,88)$ para a carne de macho castrado foi superior $(\mathrm{p}=0,0008)$ ao da carne de fêmea $(83,90)$ e de macho inteiro $(73,60)$. Em relação ao primeiro dia post mortem, o valor para a carne de macho castrado foi superior aos das carnes de fêmea e macho inteiro. Nos dias seguintes de maturação não foram encontradas diferenças significativas neste parâmetro devido ao sexo do animal. Os valores médios de IFM para o sétimo e décimo quarto dia post mortem foram, respectivamente, 114,73 e 127,89. Estes valores encontrados correspondem a uma carne macia. Segundo CULLER et al. [10], carnes com valores de IFM acima de 60 são consideradas de textura satisfatória.

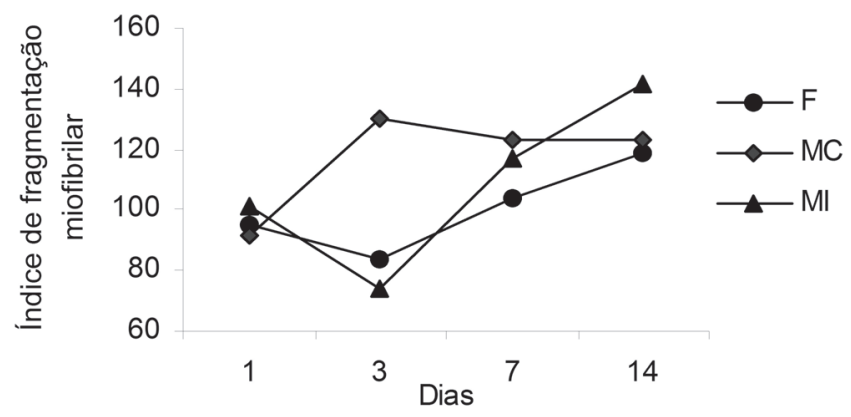

FIGURA 2. Valores do índice de fragmentação miofibrilar da carne ovina proveniente de fêmea $(\mathrm{F})$, macho castrado (MC) e macho inteiro (MI), mantida durante 14 dias de maturação a $2^{\circ} \mathrm{C}$.

O IFM é uma medida do tamanho médio das miofibrilas e está relacionado com a textura da carne. Durante a estocagem postmortem ocorre um enfraquecimento das miofibrilas e, portanto, uma fragmentação destas na banda I acontece durante a fase de homogeneização das amostras de carne [44]. Segundo os resultados obtidos por KOOHMARAIE et al. [25], o processo de fragmentação das miofibrilas é mediado pelo $\mathrm{Ca}^{2+}$, através da ativação das calpaínas. Esses autores relataram que o IFM não muda quando o músculo é incubado com uma solução contendo EDTA e EGTA, compostos quelantes do $\mathrm{Ca}^{2+}$. Ao contrário, o IFM aumenta quando os músculos são incubados com solução contendo cálcio.

Vários estudos reportaram que o IFM na carne aumenta continuamente durante o tratamento de maturação $[25,31,44,46]$. Os valores aqui encontrados situam-se acima dos reportados por KOOHMARAIE et al. [25] que verificaram um aumento no IFM de 46,2 no dia 1 até 63,5 no dia 7 e por MORGAN et al. [31] que observaram um IFM de 28,6 no dia 1 e de 72,9 no dia 14 , ambos no músculo Longissimus bovino. Já FAROUK, PRICE \& SALIH [14], trabalhando com o músculo Longissimus ovino, encontraram um valor para IFM, após 24 horas da morte do animal, de 64,71. Os dados obtidos neste estudo foram similares aos encontrados por TAYLOR et al. [44] no músculo Semimembranosus bovino. Estes autores afirmaram que o valor absoluto do
IFM pode variar bastante entre animais, mas o importante é o aumento do IFM após a morte do animal.

MORGAN et al. [31] também observaram que o músculo bovino Longissimus de macho inteiro tinha um menor IFM do que o de castrado, estando o IFM altamente correlacionado com a textura da carne.

\section{3 - Perdas na cocção}

Os dados referentes às perdas na cocção podem ser visualizados na Figura 3. As porcentagens de perdas na cocção em média variaram entre 17,67 e 24,59\%, e não houve efeito significativo do tempo de maturação sobre este parâmetro. Com relação ao efeito do sexo, foram observadas perdas maiores $(\mathrm{p}=0,0006)$ na carne de macho inteiro em relação à de macho castrado. As perdas na cocção da carne de fêmea não foram significativamente diferentes das demais. SAÑUDO et al. [38] também não observaram diferença apreciável nas perdas por cocção da carne de ovinos macho e fêmea. KEMP et al. [23] e SUMMERS et al. [43], por outro lado, não encontraram maiores diferenças entre a carne ovina de fêmea e a de macho castrado.

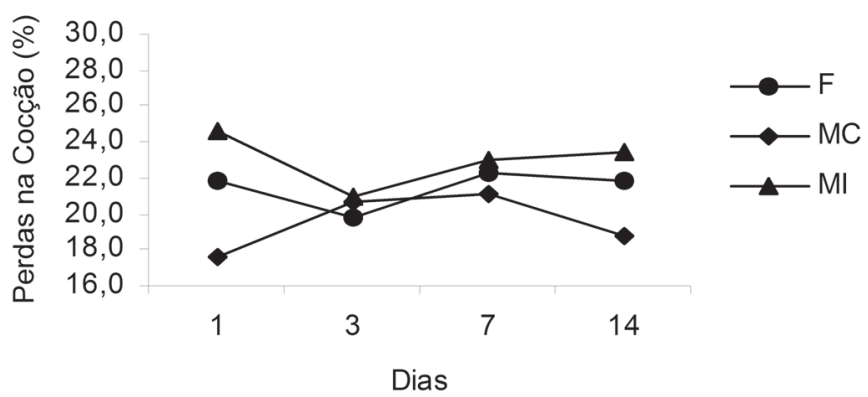

FIGURA 3. Porcentagem de perdas na cocção da carne ovina proveniente de fêmea $(\mathrm{F})$, macho castrado (MC) e macho inteiro (MI), mantida durante 14 dias de maturação a $2^{\circ} \mathrm{C}$

A porcentagem de perdas na cocção da carne de macho inteiro $(22,95)$ foi superior a de macho castrado $(19,55)$, provavelmente devido o $\mathrm{pH}$ da carne de macho inteiro ser inferior e o conteúdo de gordura ser menor. A redução da capacidade de retenção de água ocorre quando o pH muscular diminui após a morte do animal e se aproxima cada vez mais do ponto isoelétrico das proteínas miofibrilares. Quando isso ocorre, as cargas elétricas das proteínas miofibrilares tendem a se atrair e não mais se ligar com a água [18]. Como encontrado no presente trabalho, SAÑUDO et al. [36] estudando o efeito da raça sobre a qualidade da carne, verificaram que as perdas na cocção foram menores nas carnes com maior conteúdo de gordura.

Os valores observados para perdas na cocção foram inferiores aos encontrados por alguns autores com o músculo Longissimus de ovinos. SHACKELFORD, WHEELER \& KOOHMARAIE [40] relataram valor médio de $29,8 \%$ após 7 dias de maturação, enquanto DUCKETT et al. [12] encontraram para a carne de macho castrado, após 14 dias de maturação, uma porcentagem de 28,2. JEREMIAH, TONG \& GIBSON [22] estudando os 
efeitos da maturação em carne embalada a vácuo, reportaram valores de 31,03\% após 6 dias de maturação, tendo este valor aumentado de modo significativo para 34,80 e $37,29 \%$ após 27 e 41 dias de estocagem a $1^{\circ} \mathrm{C}$, respectivamente. Resultados similares foram obtidos por ZAPATA et al. [51] que reportaram valores na carne de macho inteiro, dos cruzamentos Somalis Brasileira x Crioula e Santa Inês x Crioula, variando entre 21,45 e 23,90\%. Já SAÑUDO et al. [36] trabalhando com raças espanholas (Churra, Castellana, Manchega e Awassi) observaram valores inferiores $(12,00$ a $16,02 \%)$ aos aqui reportados.

\section{4 - Força de cisalhamento}

Não houve efeito do tempo de maturação sobre a força de cisalhamento. A carne proveniente de macho inteiro, porém, teve média de $4,17 \mathrm{~kg}$ e foi superior $(\mathrm{p}=0,0001)$ a de macho castrado $(3,50 \mathrm{~kg})$ e a de fêmea $(3,24 \mathrm{~kg})$, sendo que estas duas últimas não diferiram entre si (Figura 4). Segundo a classificação realizada por BOLEMAN et al. [6], a carne de macho inteiro pode ser definida como moderadamente macia, enquanto que a de macho castrado e a de fêmea como muito macia. Todas as carnes analisadas neste trabalho encontramse abaixo do limite máximo de força de cisalhamento desejável para a comercialização, de acordo com SHACKELFORD et al. [39].

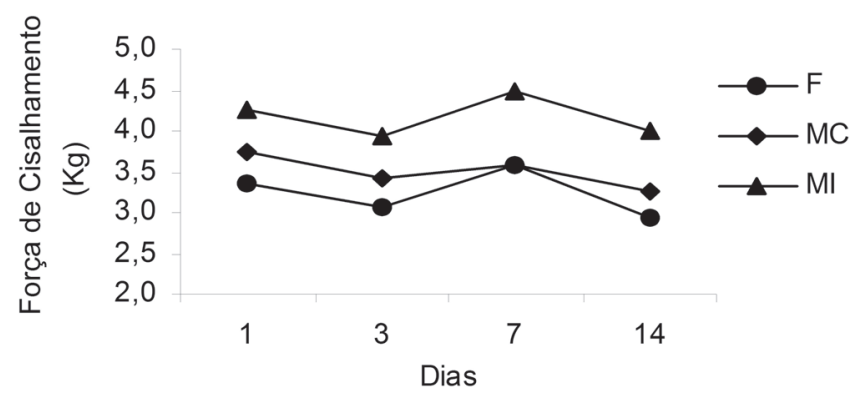

FIGURA 4. Valores da força de cisalhamento da carne ovina proveniente de fêmea $(\mathrm{F})$, macho castrado $(\mathrm{MC})$ e macho inteiro (MI), mantida durante 14 dias de maturação a $2^{\circ} \mathrm{C}$.

KEMP et al. [23] e SUMMERS et al. [43], trabalhando com carne ovina, também não encontraram diferenças entre a carne de macho castrado e a de fêmea. SAÑUDO et al. [38], ao contrário do observado neste trabalho, não encontraram diferença apreciável entre macho inteiro e fêmea, quanto a força de cisalhamento dessas carnes. Esses autores trabalharam com animais ovinos de aproximadamente 78 dias de idade, enquanto neste experimento, os animais com aproximadamente 15 meses de idade já haviam completado a maturidade. A menor maciez encontrada na carne dos machos inteiros pode ser atribuída, por um lado, a uma maior concentração e maturidade do colágeno intramuscular neste tipo de animais e, por outro, a uma menor degradação proteolítica após a morte. Talvez, o colágeno intramuscular apresente-se numa proporção relativamente maior em ani- mais mais velhos do que nos mais novos, sendo esta a causa provável da diferença entre os resultados encontrados neste estudo e os obtidos por SAÑUDO et al. [38]. Similarmente ao observado nesta pesquisa, MORGAN et al. [31] analisando a textura da carne bovina, reportaram diferenças significativas na força de cisalhamento das carnes dos machos inteiro e castrado.

No geral, os trabalhos realizados com carne ovina demonstraram uma diminuição da força de cisalhamento 24 horas post mortem durante a maturação [12, 25, 26, 48]. Essa diminuição na força de cisalhamento provavelmente não foi observada nesta pesquisa, pelo fato dos valores encontrados no primeiro dia post mortem para macho inteiro, macho castrado e fêmea de 4,25, 3,74 e 3,35kg, respectivamente, já serem suficientemente baixos. Os valores para força de cisalhamento 24 horas post mortem no músculo ovino Longissimus reportados por FAROUK, PRICE \& SALIH [14], KOOHMARAIE et al. [24] e WHEELER \& KOOHMARAIE [48] foram de 8,19; 7,60 e $5,79 \mathrm{~kg}$, respectivamente. Os demais valores relatados neste estudo são similares aos observados por diversos autores, no músculo ovino Longissimus. SAÑUDO et al. [38] encontraram valores de $3,89 \mathrm{~kg}$ para a carne de macho inteiro e de $3,62 \mathrm{~kg}$ para a de fêmea no terceiro dia post mortem. Após 7 dias da morte de ovinos machos castrados KOOHMARAIE, DOUMIT \& WHEELER [26] e SHACKELFORD et al. [39] reportaram valores de 3,34 e $4,50 \mathrm{~kg}$, respectivamente. FIELD et al. [15] e TAYLOR \& KOOHMARAIE [45] verificaram valores de 2,86 e 2,80kg, respectivamente, na carne ovina após 14 dias de maturação.

\section{5 - Gordura intramuscular}

Na Figura 5 encontram-se os valores de percentagem de gordura intramuscular dos ovinos estudados. Os machos castrados apresentaram em média 3,76\% seguido das fêmeas com 3,28\% e dos machos inteiros com $2,40 \%$. Apenas a diferença entre os valores para machos castrados e machos inteiros foi significativa ( $\mathrm{p}=0,0431)$. Os valores obtidos para machos inteiros e fêmeas não apresentaram diferença significativa provavelmente devido ao pequeno número de amostras $(n=5)$ para cada sexo.

HORCADA et al. [19], estudando o efeito do sexo sobre a qualidade da carne ovina comercializada na Espanha, encontraram valores de gordura intramuscular menores para a carne de macho inteiro em relação à de fêmea. Esses valores para macho inteiro e fêmea foram, respectivamente, de 1,87 e 2,74 \% para a raça Lacha e 3,15 e 3,54\% para a raça Aragonesa. CROUSE et al. [9] também reportaram menores porcentagens de gordura na carne de macho inteiro $(2,73)$ que na de fêmea $(3,59)$. A carne proveniente de macho inteiro é reconhecida como de baixo conteúdo de gordura. Segundo HEDRICK et al. [18] esta variação na qualidade da carne entre animais de condição sexual diferente se deve basicamente aos diferentes níveis de hormônios sexuais. 


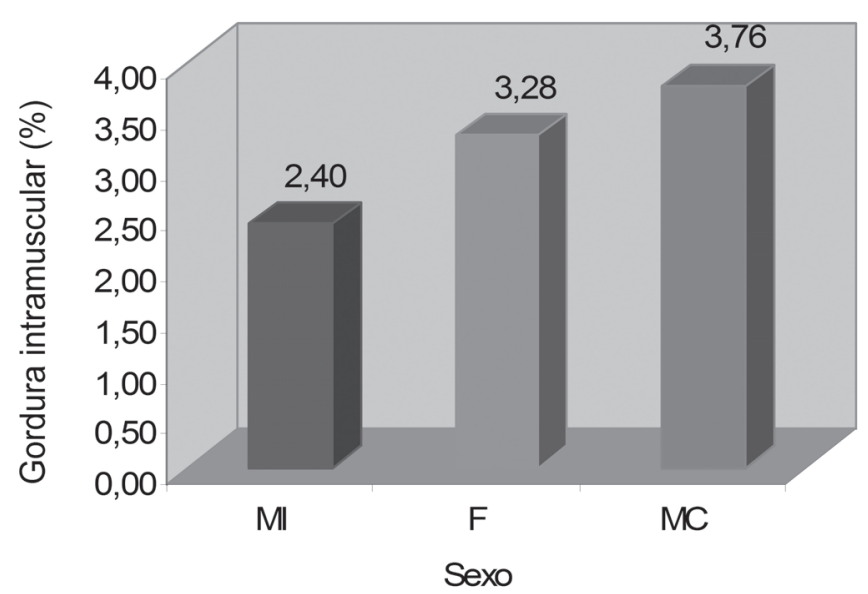

FIGURA 5. Porcentagem de gordura intramuscular da carne ovina proveniente de macho inteiro (MI), fêmea (F) e macho castrado (MC) mantida durante 14 dias de maturação a $2^{\circ} \mathrm{C}$.

Valores de gordura intramuscular próximos ao deste estudo foram verificados por outros autores. ZAPATA et al. [50] encontraram porcentagens de gordura intramuscular entre 2,01 e 2,39 para a carne de macho inteiro proveniente de ovinos de raças características do Nordeste brasileiro. GARCIA, SOBRINHO \& ROÇA [16] verificaram valores de gordura entre 1,41 e 3,00 \% para ovinos machos inteiros $1 / 2$ Texel $1 / 2$ SRD e ALMEIDA [3] relatou porcentagens de $4,25 \%$ na carne de ovinos Morada Nova.

A maior porcentagem de gordura nas carnes de fêmea e de macho castrado do que na de macho inteiro coincide com os resultados obtidos na análise de textura instrumental e sensorial. A carne com maior conteúdo de gordura intramuscular apresentou também menor força de cisalhamento e melhor maciez, segundo a análise sensorial realizada.

\section{6 - Cor da carne ovina}

Os valores médios de $\mathrm{L}^{*}$ obtidos neste estudo variaram entre 30,24 e 34,02 (Figura 6). Estes valores mantiveram-se praticamente constantes durante os 14 dias de maturação. De acordo com a análise de variância, não houve interação entre o sexo e o tempo de maturação, nem foi encontrada diferença significativa nos dois efeitos estudados. HORCADA et al. [19], estudando o efeito do sexo sobre as características da carne proveniente de raças espanholas, também não verificaram efeito do sexo sobre o componente de luminosidade. Entretanto, SAÑUDO et al. [38] observaram diferenças estatísticas nos valores de $\mathrm{L}^{*}$ encontrados para as carnes de macho inteiro $(41,26)$ e fêmea $(39,80)$.

Em geral, os dados obtidos para a variável $\mathrm{L}^{*}$ foram inferiores aos reportados na literatura $[19,36,37,38$, $41,50]$. Contudo, as carnes ovinas avaliadas por esses autores eram procedentes de animais mais novos do que os do presente experimento. SAÑUDO et al. [37], estudando a influência do peso da carcaça sobre a qualidade da carne, verificaram que as carnes dos ovinos mais leves tinham maiores valores de $L^{*}(48,15)$ do que as de animais mais pesados $(45,61)$. Os autores sugeriram que essas variações poderiam ser causadas pelas diferentes idades na hora do abate e tipo de alimentação.

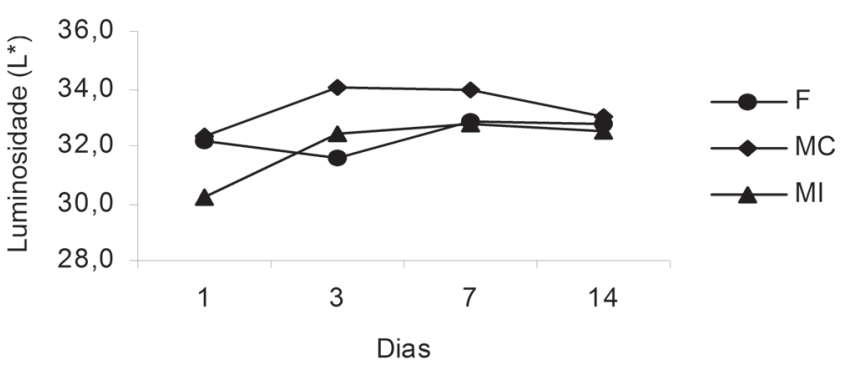

FIGURA 6. Valores de luminosidade (L*) da carne ovina proveniente de fêmea $(F)$, macho castrado $(M C)$ e macho inteiro (MI), mantida durante 14 dias de maturação a $2^{\circ} \mathrm{C}$.

A variável a* indica a intensidade da cor vermelha e está relacionada com o conteúdo de mioglobina no músculo, quanto maior for o seu valor, mais vermelha será a carne [36]. Em média, o valor mínimo encontrado foi de 14,30 no terceiro dia de maturação, enquanto que o máximo foi de 17,19 no primeiro dia de maturação para carne de macho inteiro (Figura 7). Da mesma forma que a variável $\mathrm{L}^{*}$, a análise de variância para $\mathrm{a}^{*}$ demonstrou não haver interação entre o sexo e o tempo de maturação, nem diferença significativa nos dois efeitos estudados. Como observado nesta pesquisa, HORCADA et al. [19] e SAÑUDO et al. [38] também não encontraram diferenças apreciáveis entre as carnes de macho e de fêmea para a variável a*.

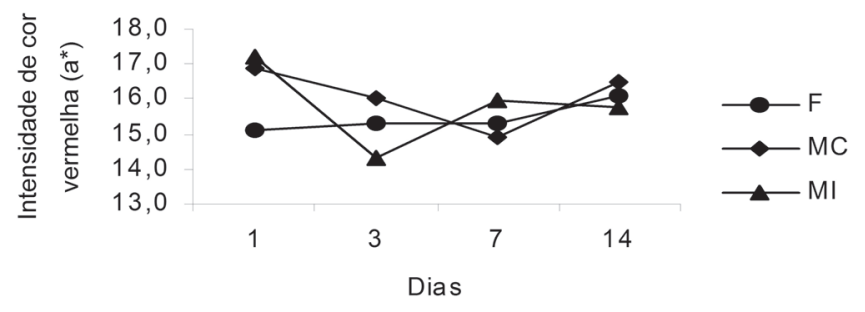

FIGURA 7. Valores da intensidade da cor vermelha (a*) da carne ovina proveniente de fêmea (F), macho castrado (MC) e macho inteiro (MI), mantida durante 14 dias de maturação a $2^{\circ} \mathrm{C}$.

Os valores de a* obtidos por SAÑUDO et al. [37, 38] para animais ovinos da raça Aragonesa e por ZAPATA et al. [51] para animais ovinos típicos do Nordeste brasileiro foram similares aos encontrados neste trabalho. Entretanto, HORCADA et al. [19] e SAÑUDO et al. [36], trabalhando com diversas raças ovinas típicas dos países do Mediterrâneo, encontraram valores de a* abaixo de 10,0. Carnes ovinas de animais jovens, de cor vermelha suave, são tradicionalmente produzidas e consumidas nestes países. 
As carnes de animais mais jovens possuem valores de $\mathrm{a}^{*}$ mais baixos, possivelmente pelas diferentes idades de abate e dietas a que estes são submetidos. Animais mais jovens recebem proporcionalmente mais leite, com baixo conteúdo de ferro, resultando em uma menor quantidade de mioglobina na carne.

Com relação a variável b*, a qual indica a intensidade de cor amarela, os valores médios obtidos variaram entre 1,87 e 3,67 (Figura 8), sem que tenha sido observado efeito significativo do sexo do animal ou do tempo de maturação da carne.

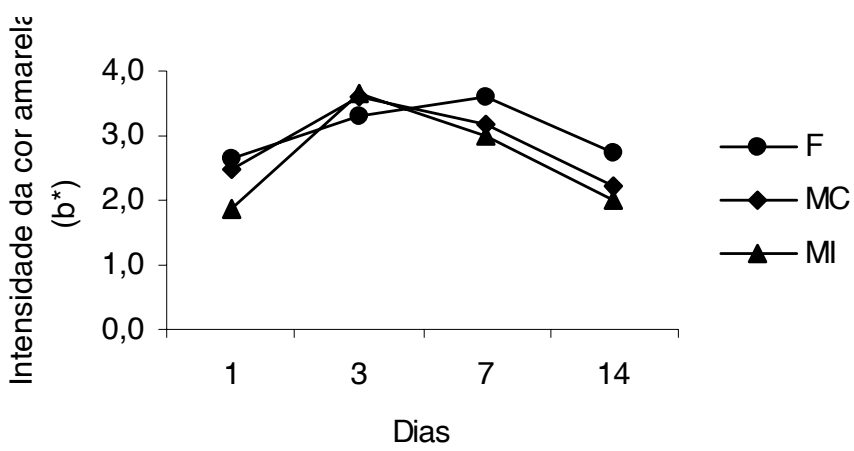

FIGURA 8. Valores da intensidade da cor amarela (b*) da carne ovina proveniente de fêmea $(\mathrm{F})$, macho castrado (MC) e macho inteiro (MI), mantida durante 14 dias de maturação a $2^{\circ} \mathrm{C}$.

HORCADA et al. [19] e SAÑUDO et al. [38], estudando o efeito do sexo sobre as características da carne ovina, também não encontraram diferença significativa sobre a variável b*. Os valores reportados por esses autores, assim como os obtidos por SAÑUDO et al. [36, 37] e SIMMONS et al. [41], variaram entre 5,90 e 10,75. Esses resultados, bem acima dos encontrados neste estudo, indicaram que as tonalidades de vermelho nestas carnes estão mais perto da região do amarelo, diferentemente da cor mais perto da região do cinza obtida nesta pesquisa.

ZAPATA et al. [51] reportaram valores de $b^{*}$ entre 0,83 e 1,37 em carnes de ovinos provenientes de cruzamentos Somalis Brasileira e Crioula, e Santa Inês e Crioula, que se aproximaram dos resultados obtidos neste trabalho.

\section{7 - Análise da maciez sensorial da carne}

Os resultados da análise sensorial para a característica de maciez da carne indicou que a de macho castrado alcançou o maior total ordenado (91), segundo os provadores, seguido da carne de fêmea (90) e da de macho inteiro (59). Utilizando a tabela de Newell e Mac Farlaine, verificou-se que não houve diferença significativa $(p>0,05)$ entre os dois maiores totais ordenados. Mas, tanto a carne de fêmea como a de macho castrado foram significativamente $(\mathrm{p}<0,05)$ mais macias que a de macho inteiro. A menor maciez da carne de macho inteiro confirmou os resultados obtidos na análise de textura instrumental, indicando que os provadores foram capazes de detectar pequenas diferenças na resistência ao corte das carnes. DEVINE et al. [11] observaram uma relação linear entre a análise sensorial e a força de cisalhamento, com coeficiente de regressão de 0,7.

Como observado nesta pesquisa, KEMP et al. [23] e SUMMERS et al. [43] também não verificaram diferença no atributo maciez entre a carne de macho castrado e a de fêmea. MORGAN et al. [31] estudando a textura da carne bovina, observaram apenas uma tendência $(\mathrm{p}<0,07)$ da carne de macho castrado possuir melhor textura que a de macho inteiro nos resultados obtidos na análise sensorial.

\section{4 - CONCLUSÕES}

O sexo do animal influiu sobre a qualidade da carne ovina. As carnes de macho castrado e de fêmea apresentaram melhor textura do que a carne de macho inteiro, como demonstraram os resultados das análises instrumental e sensorial para este atributo.

A carne de macho castrado quando comparada à de macho inteiro apresentou maior conteúdo de gordura e menores perdas na cocção.

O tempo de maturação de até 14 dias não afetou os parâmetros estudados da carne de animais ovinos do tipo SRD. Portanto, os produtores regionais poderão oferecer carnes ovinas frescas de qualidade mediante um curto período de 24 horas de acondicionamento sob refrigeração a $2^{\circ} \mathrm{C}$.

\section{5 - REFERÊNCIAS BIBLIOGRÁFICAS}

[1] ABNT - Associação Brasileira de Normas Técnicas. Teste de ordenação em análise sensorial. NBR 13170. Rio de Janeiro, 1994.

[2] ABUlaRACH, M.L.S.; ROCHA, C.E.; FELÍCIO, P.E. Características de qualidade do contrafilé (m. L. dorsi) de touros jovens da raça Nelore. Ciênc. Tecnol. Aliment. v. 18 , n. 2, p. 205-210, 1998.

[3] ALMEIDA, M.M.M. Estudo da composição química das carnes de caprinos e ovinos no sertão do Ceará. Fortaleza: 1990. 78 p. Dissertação (Mestrado em Tecnologia de Alimentos). Centro de Ciências Agrárias, Universidade Federal do Ceará (UFC).

[4] AOAC. Association of Official Analytical Chemists. Official Methods of Analysis, $15^{\text {th }}$ ed. Association of Official Analytical Chemists, Inc., Arlington, 1990. 1250p.

[5] BELTRÁN, J.A.; JAIME, I.; SANTOLARIA, P.; SAÑUdO, C.; ALBERTI, P.; RONCALÉS, P. Effect of stressinduced high post-mortem $\mathrm{pH}$ on protease activity and tenderness of beef. Meat Sci., v. 45, n. 2, p. 201-207, 1997.

[6] BOLEMAN, S.J.; BOLEMAN, S.L.; MILLER, R.K.; TAYLOR, J.F.; CROSS, H.R.; WHEELER, T.L.; KOOHMARAIE, M.; SHACKELFORD, S.D.; MILLER, M.F.; WEST, R.L.; JOHNSON, D.D.; SAVELL, J.W. Consumer evaluation of beef of known categories of tenderness. J. Anim. Sci. v. 75, n. 6, p. 1521-1524, 1997.

[7] BRASIL. MINISTÉRIO DA AGRICULTURA. Regulamento da Inspeção Industrial e Sanitária de Produtos de Origem Animal. Ministério da Agricultura, Brasília, 1997. 
[8] BUSSAB, W.O.; MORETTIN, P.A. Estatística Básica. 4. ed. São Paulo: Atual, 1987. 320p.

[9] CROUSE, J.D.; FIELD, R.A.; CHANT, J.L.; FERREL, C.L.; SMITH, G.M.; HARRISON, V.L. Effect of dietary energy intake on carcass composition and palatability of different weight carcasses from ewe and ram lambs. J. Anim. Sci., v. 47, n. 6, p. 1207-1218, 1978.

[10] CULLER, R.D.; PARRISH JR.; F.C.; SMITH, G.C.; CROSS, H.R. Relationship of myofibril fragmentation index to certain chemical, physical and sensory characteristics of bovine longissimus muscle. J. Food Sci., v. 43, n. 4, p. 1177-1180, 1978

[11] DEVINE, C.E.; GRAAFHUIS, A.E.; MUIR, P.D.; CHRYSTALL, B.B. The effect of growth rate and ultimate $\mathrm{pH}$ on meat quality of lambs. Meat Sci., v. 35, n. 1, p. 63-77, 1993

[12] DUCKETT, S.K.; KLEIN, T.A.; DODSON, M.V.; SNOWDER, G.D. Tenderness of normal and callipyge lamb aged fresh or after freezing. Meat Sci., v. 49, n. 1, p. 19-26, 1998a.

[13] DUCKETT, S.K.; KLEIN, T.A.; LECKIE, R.K.; THORNGATE, J.H.; BUSBOOM, J.R.; SNOWDER, G.D. Effect of freezing on calpastatin activity and tenderness of callipyge lamb. J. Anim. Sci., v. 76, n. 7, p. 1869-1874, 1998b.

[14] FAROUK, M.M.; PRICE, J.F.; SAliH, A.M. Postexsanguination infusion of ovine carcasses: effect on tenderness indicators and muscle microstructure. J. Food Sci., v. 57, n. 6, p. 1311-1315, 1992.

[15] FIELD, R.A.; McCORMICK, R.J.; BROWN, D.R.; HINDS, F.C.; SNOWDER, G.D. Collagen crosslinks in longissimus muscle from lambs expressing the callipyge gene. J. Anim. Sci., v. 74, n. 12, p. 2943-2947, 1996.

[16] GARCIA, C.A.; SOBRINHO, A.G.S.; ROCA, R.O Mensurações e análise química do músculo Longissimus dorsi de ovinos confinados sob diferentes dietas. In: Reunião da Sociedade Brasileira de Zootecnia, 35, 1998, Botucatu-SP. Anais... Botucatu: Sociedade Brasileira de Zootecnia, p. 582-584, 1998.

[17] GORNALL, A.G.; BARDAWILL, C.J.; DAVID, M.M Determination of serum protein by means of the biuret reaction. J. Biol. Chem., v. 177, n. 2, p. 751-766, 1949.

[18] HEDRICK, H.B.; ABERLE, E.D.; FORREST, J.C.; JUDGE, M.D.; MERKEL, R.A. Principles of Meat Science. 3.ed. Iowa: Kendall/Hunt Publishing Company, 1994. 354p.

[19] HORCADA, A.; BERIAIN, M.J.; PURROY, A.; LIZASO, G.; CHASCO, J. Effect of sex on meat quality of Spanish lamb breeds (Lacha and Rasa Aragonesa). Animal Science., v. 67, n. 3, p. 541-547, 1998.

[20] HUFF, E.J.; PARRISH JR. F.C. Bovine longissimus muscle tenderness as affected by postmortem aging time, animal age and sex. J. Food Sci., v. 58, n. 4, p. 713-716, 1993.

[21] HUFF-LONERGAN, E.; MITSUHASHI, T.; BEEKMAN, D.D.; PARRISH Jr., F.C.; OLSON, D.G.; ROBSON, R.M. Proteolysis of specific muscle strutural proteins by $\mathrm{m}$ calpain at low $\mathrm{pH}$ and temperature is similar to degradation in postmortem bovine muscle. J. Anim. Sci., v. 74, n. 5, p. 993-1008, 1996.

[22] JEREMIAH, L.E.; TONG, A.K.W.; GIBSON, L.L. Hotboning, elevated temperature conditioning, and vacuum packaged aging influences on lamb cooking losses and palatability. J. Food Sci., v. 62, n. 5, p. 1026-1027, 1997.
[23] KEMP, J.D.; ELY, D.G.; FOX, J.D; MOODY, W.G. Carcass and meat characteristics of crossbred lambs with and without finnish landrace breeding. J. Anim. Sci., v. 52, n. 5, p. 1026-1033, 1981.

[24] KOOHMARAIE, M.; BABIKER, A.S.; MERKEL, R.A.; DUTSON, T.R. Role of Ca-dependent proteases and lysosomal enzymes in postmortem changes in bovine skeletal muscle. J. Food Sci., v. 53, n. 5, p. 1253-1257, 1988a.

[25] KOOHMARAIE, M.; BABIKER, A.S.; SCHROEDER, A.L.; MERKEL, R.A.; DUTSON, T.R. Acceleration of postmortem tenderization in ovine carcasses through activation of $\mathrm{Ca}^{2}$-dependent proteases. J. Food Sci., v. 53 , n. 6 , p. $1638-1641,1988$ b.

[26] KOOHMARAIE, M.; DOUMIT, M.E.; WHEELER, T.L. Meat toughening does not occur when rigor shortening is prevented. J. Anim. Sci., v. 74, n. 12, p. 2935-2942, 1996.

[27] LAWRIE, R.A. Meat Science. 4.ed. Oxford: Pergamon Press, 1985. 267p.

[28] LOWE, T.E.; PEACHEY, B.M.; DEVINE, C.E. The effect of nutritional supplements on growth rate, stress responsivness, muscle glycogen and meat tenderness in pastoral lambs. Meat Sci., v. 62, n. 4, p. 391-397, 2002.

[29] McKEITH, F.K.; LAN, Y.H.; BEERMANN, D.H. Sensory characteristics of meat from animals given partitioning agents. In: HAFS, H.D., ZIMBELMAN, R.G. (Editores). Low-fat meats: design strategies and human implications. New York: Academic Press, 1994. 328p.

[30] MINOLTA Co., Precise Color Communication - color control from perception to instrumentation. Osaka: Minolta Co., Ltd., 1998. 59p.

[31] MORGAN, J.B., WHEELER, T.L., KOOHMARAIE, M., SAVELL, J.W., CROUSE, J.D. Meat tenderness and the calpain proteolytic system in longissimus muscle of young bulls and steers. J. Anim. Sci., v. 71 , n. 6 , p. 1471-1476, 1993.

[32] NETER, J.; WASSERMAN, W. Applied linear statistical models. Homewwod: Richard D. Irwin Inc., 1974. 842p.

[33] OTREMBA, M.M.; DIKEMAN, M.E.; MILIKEN, G.A.; STRODA, S.L.; UNRUH, J.A.; CHAMBERS IV, E. Interrelantionships among evaluations of beef longissimus and semitendinosus muscle tenderness by Warner-Bratzler shear force, a descriptive texture profile sensory panel, and a descriptive attribute sensory panel. J. Anim. Sci., v. 77, n. 4, p. 865-873, 1999.

[34] PRATES, J.A.M.; COSTA, F.J.S.G.; RIBEIRO, A.M.R.; CORREIA, A.A.D. Contribution of major structural changes in myofibrils to rabbit meat tenderisation during ageing. Meat Sci., v. 61, n. 1, p. 103-113, 2002.

[35] SAINZ, R.D. Gualidade das carcaças e da carne ovina e caprina. In: Reunião Anual da Sociedade Brasileira de Zootecnia, 1996, Fortaleza-CE. Anais... Fortaleza: Sociedade Brasileira de Zootecnia, p. 3-19, 1996.

[36] SAÑUDO, C.; CAMPO, M.M.; SIERRA, I.; MARÍA, G.A.; OLLETA, J.L.; SANTOLARIA, P. Breed effect on carcass and meat quality of suckling lambs. Meat Sci., v. 46, n. 4, p. 357-365, 1997.

[37] SAÑUDO, C.; SANTOLARIA, M.P.; MARIA, G.; OSORIO, M.; SIERRA, I. Influence of carcass weight on instrumental and sensory lamb meat quality in intensive production systems. Meat Sci., v. 42, n. 2, p. 195-202, 1996.

[38] SAÑUDO, C.; SIERRA, I.; OLLETA, J.L.; MARTIN, L.; CAMPO, M.M.; SANTOLARIA, P.; WOOD, J.D.; NUTE, 
G.R. Influence of weaning on carcass quality, fatty acid composition and meat quality in intensive lamb production systems. Animal Science, v. 66, p. 175-187, 1998.

[39] SHACKELFORD, S.D.; MORGAN, J.B.; CROSS, H.R.; SAVELL, J.W. Identification of threshold levels for Warner-Bratzler shear force in beef top loin steaks. J. Muscle Foods, v. 2, p. 289, 1991.

[40] SHACKELFORD, S.D.; WHEELER, T.L.; KOOHMARAIE, $M$. Effect of the callipyge phenotype and cooking method on tenderness of several major lamb muscles. J. Anim. Sci., v. 75, n. 8, p. 2100-2105, 1997.

[41] SIMMONS, N.J.; YOUNG, O.A.; DOBBIE, P.M.; SINGH, K.; THOMPSON, B.C.; SPECK, P.A. Post-mortem calpain-system kinetics in lamb: effects of clenbuterol and preslaughter exercise. Meat Sci., v. 47, n. 1/2, p. 135-146, 1997.

[42] STONE, H.; SIDEL, J.L. Sensory Evaluation Practices. Orlando: Academic Press, 1985. $311 \mathrm{p}$.

[43] SUMMERS, R.L.; KEMP, J.D.; ELY, D.G.; FOX, J.D. Effects of weaning, feeding systems and sex of lamb on lamb carcass characteristics and palatability. $\mathbf{J}$. Anim. Sci., v. 47, n. 3, p. 622-629, 1978.

[44] TAYLOR, R.G.; GEESINK, G.H.; THOMPSON, V.F.; KOOHMARAIE, M.; GOLL, D.E. Is Z-disk degradation responsible for postmortem tenderization?. J. Anim. Sci., v. 73, n. 5, p. 1351-1367, 1995.

[45] TAYLOR, R.G.; KOOHMARAIE, M. Effects of postmortem storage on the ultrastruture of the endomysium and myofibrils in normal and callipyge longissimus. $\mathbf{J}$. Anim. Sci., v. 76, n. 11, p. 2811-2817, 1998.
[46] WATANaBE, A.; DALY, C.C.; DEVINE, C.E. The effects of the ultimate $\mathrm{pH}$ of meat on tenderness changes during ageing. Meat Sci., v. 42, n. 1, p. 67-78, 1996.

[47] WHEELER, T.L.; KOOHMARAIE, M. Prerigor and postrigor changes in tenderness of ovine longissimus muscle. J. Anim. Sci., v. 72, n. 5, p. 1232-1238, 1994.

[48] WHEELER, T.L.; KOOHMARAIE, M. The extent of proteolysis is independent of sarcomere length in lamb longissimus and psoas major. J. Anim. Sci., v. 77, n. 9, p. 2444-2451, 1999.

[49] ZAPATA, J.F.F. Tecnologia e Comercialização de Carne Ovina. In: LEITE, E.R. (Editor). Semana da Caprinocultura e da Ovinocultura Tropical Brasileira, 1994, Sobral, CE. Anais... Sobral: EMBRAPACNPC, 1994. p.115-128

[50] ZAPATA, J.F.F.; NOGUEIRA, C.M.; SEABRA, L.M.J.; BARROS, N.; BORGES, A.S. Composição centesimal e lipídica da carne de ovinos do Nordeste Brasileiro. Ciência Rural, Santa Maria, v. 31, n. 4, p. 691-695, 2001.

[51] ZAPATA, J.F.F.; SEABRA, L.M.J.; NOGUEIRA, C.M.; BARROS, N. Estudo da qualidade da carne ovina do Nordeste brasileiro: propriedades físicas e sensoriais. Ciên. Tecnol. Aliment., Campinas, v. 20, n. 2, p. 274-277, 2000.

\section{6 - AGRADECIMENTOS}

Os autores agradecem o apoio financeiro do Conselho Nacional de Desenvolvimento Científico e Tecnológico (CNPq). 